\title{
A WEB-BASED LEARNING ENVIRONMENT OF REMOTE SENSING EXPERIMENTAL CLASS WITH PYTHON
}

\author{
Jun $\mathrm{Li}^{1}$, Jianlong Sheng ${ }^{1,}$, Yong Chen ${ }^{1}$, Lihua $\mathrm{Ke}^{1}$, Nan Yao ${ }^{1}$, Zuohua Miao ${ }^{1}$, Xiangyang Zeng ${ }^{1}$, Lin Hu ${ }^{1}$, Qiaozhi Wang ${ }^{1}$ \\ ${ }^{1}$ College of Resource and Environmental Engineering, Wuhan University of Science and Technology, Wuhan, China - \\ shengjianlong@wust.edu.cn
}

Commission V, WG V/4

KEY WORDS: education, web-based learning, experimental class, python, remote sensing

\begin{abstract}
:
Remote sensing course is a general disciplinary required course of human geography and urban-rural planning major. Its class hour is 48 , including theoretical classes and experimental classes. Rapid technological developments is remote sensing area demand quick and steady changes in the education programme and its realization, especially in experimental classes. Experimental classes include: introduction to remote sensing software and basic operations, remote sensing data pre-processing (input, output, 2D and 3D terrain display, image cut, image mosaic, and projection transformation), remote sensing image enhancement, remote sensing image transformation, computer aided classification, image interpretation, and remote sensing image terrain analysis. There are two difficulties in the remote sensing experimental classes. First, it cost a lot of time to prepare the remote sensing software and the remote sensing images. Second, some students just want to use the remote sensing as a tool to investigate environment changing, some other students may want to study more remote sensing image processing technologies. A web-based learning environment of remote sensing is developed to facilitate the application of remote sensing experimental teaching. To make the learning more effective, there are eight modules including four optional modules. The Python programming language is chosen to implement the web-based remote sensing learning environment. The web-based learning environment is implemented in a local network server, including the remote sensing data processing algorithms and many satellite image data. Students can easily exercise the remote sensing experimental courses by connecting to the local network server. It is developed mainly for remote sensing experimental course, and also can be adopted by digital image processing or other courses. The feature of web-based learning may be very useful as the online education adopted because of Corona Virus Disease 2019. The results are encouraging and some recommendations will be extracted for the future.
\end{abstract}

\section{INTRODUCTION}

Remote sensing plays an important role in many fields, such as major natural disaster monitoring, global climate dynamics, primary production of terrestrial ecosystems, government decision-making, etc. Remote sensing and associated technologies have long been recognized as well suited to resource exploration, resource monitoring and change detection in development. The rapid increase in the availability of remote sensing data coupled with the increasing need for accurate and timely earth surface information especially in developing countries has accelerated the demand for and provision of technology transfer of remote sensing by many organizations and governments. Much of this increase is related to concerns for global climate change (Haack et al, 2016).

Remote sensing course mainly introduces knowledge of remote sensing technology system, electromagnetic radiation principles and ground object spectral feature, principle of remote sensing imaging and remote sensing image feature, image processing, elements of visual image interpretation and mapping, computer interpretation, multispectral remote sensing system, remote sensing application, comprehensive application of $3 \mathrm{~S}$ (remote sensing, global position system, and geographic information system), etc. ( $\mathrm{Li}$ et al, 2014.). It is a general disciplinary required course of human geography and urban-rural planning major. Its class hour is 48 , including theoretical classes and experimental classes.

Rapid technological developments is remote sensing area demand quick and steady changes in the education programme and its realization, especially in experimental classes (Wolf et al, 2016). Laboratory experimentation plays an essential role in engineering and scientific education. Experimental classes include: introduction to remote sensing software and basic operations, remote sensing data pre-processing (input, output, 2D and 3D terrain display, image cut, image mosaic, and projection transformation), remote sensing image enhancement, remote sensing image transformation, computer aided classification, image interpretation, and remote sensing image terrain analysis (Gülch et al , 2012.).

There are two difficulties in the remote sensing experimental classes. First, it cost a lot of time to prepare the remote sensing software and the remote sensing images. Second, some students just want to use the remote sensing as a tool to investigate environment changing, some other students may want to study more remote sensing image processing technologies. A web-

\footnotetext{
* Corresponding author
} 
based learning environment of remote sensing is developed to facilitate the application of remote sensing experimental teaching. To make the learning more effective, there are eight modules including four optional modules. The Python programming language and flask framework are chosen to implement the web-based remote sensing learning environment. Python code is easy to read, easy to learn still a very powerful language. Python is an open-source language, and it has libraries for just about everything, including remote sensing image data processing. The web-based learning environment is implemented in a local network server, including the remote sensing data processing algorithms and many satellite image data. Students can easily learn the remote sensing experimental courses by connecting to the local network server. Virtual and remote labs reduce the costs associated with conventional hands-on labs due to their required equipment, space, and maintenance staff. Furthermore, they provide additional benefits such as supporting web-based learning (Heradio et al, 2016).

With the popularity and improvement of information search technology, increasingly more learners choose self-learning through the Internet, which is a well-known method for elearning. Compared with the traditional teacher-oriented learning style, e-learning has advantages: the learning target can be flexibly searched and viewed by learners anywhere, not only in class (Shi et al, 2020). The World Wide Web can be used to develop university education. Specifically, resources on the
WWW which are of relevance to remote sensing have been identified (Erik, 1997). Education has grown rapidly and stimulated the adoption of e-learning, which is a direct result of the integration of education and technology and is deemed to be a powerful medium for learning (Raju, et al, 2012). The undeniable significance of e-learning in education has led to a massive growth in the number of e-learning courses and systems offering different types of services (Al-Fraihat et al, 2020). Distance learning is a field of education that focuses on the technology and instructional systems design that are effectively incorporated in delivering education to students who are not physically "on site" to receive their education. Instead, teachers and students may communicate asynchronously (at times of their own choosing) by exchanging printed or electronic media, or through technology that allows them to communicate in real time (synchronously). Computers and the Internet have only made distance learning easier, just as it has for many other dayto-day tasks (Raju et al, 2012). Corona Virus Disease 2019 (COVID-19) is a deadly respiratory viral disease that started in the year 2019. It affects everybody regardless of race, religion, social economic status or age. Many students cannot come back to university because of Corona Virus Disease 2019. E-learning tools and methods will be popular discussed (Anjana et al, 2016), and the feature of web-based learning may be very useful as the online education adopted (Yang et al, 2016.)

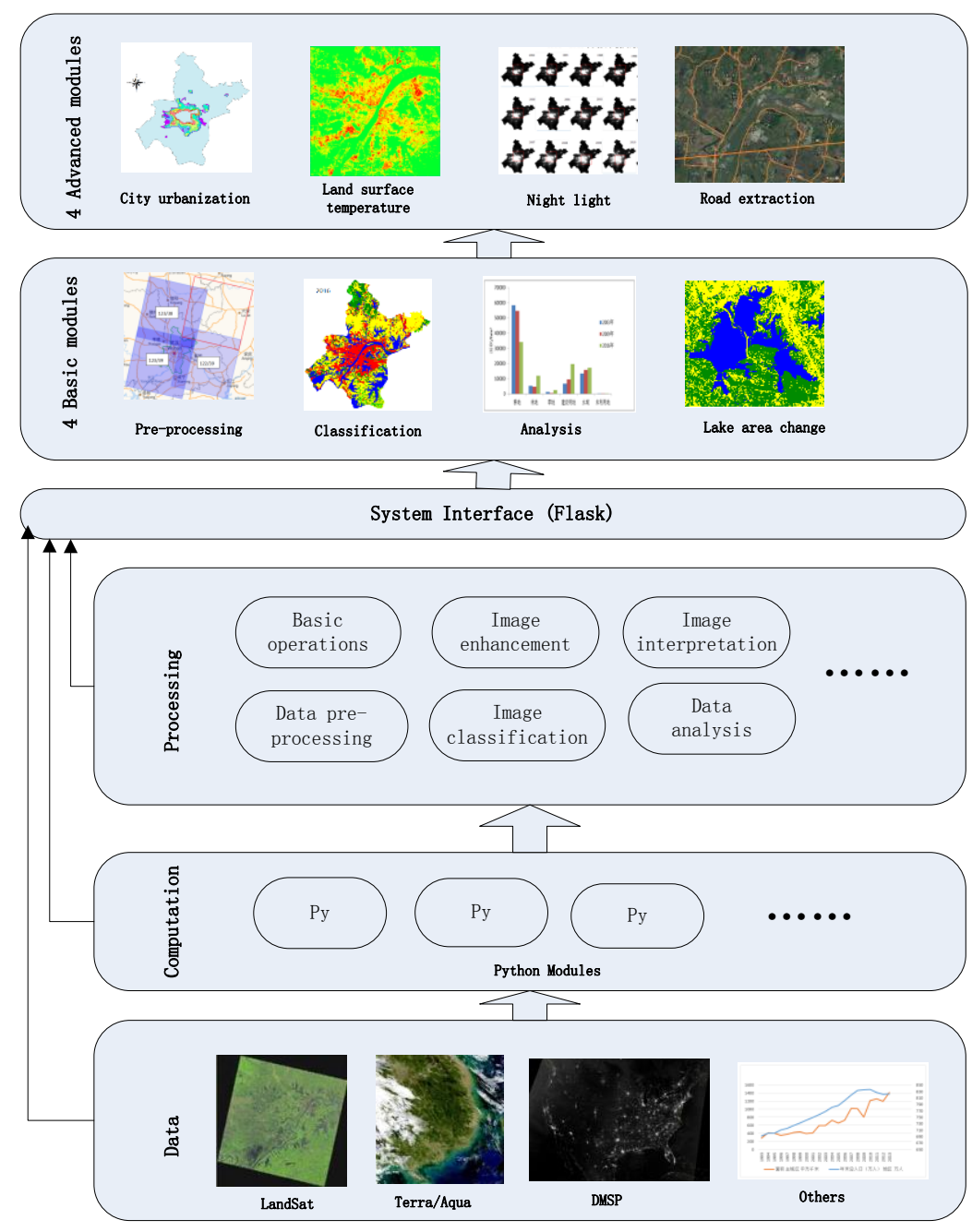

Figure 1. Architecture of the learning environment 


\section{LEARNING ENVIRONMENT}

\subsection{Architecture}

The online education is affected by services which can be found depending on certain factors. The instrument that has been used earlier in studies concerning online service quality has been adopted for the collection of data and its analysis. The architecture (Figure 1) consists of two parts: inside and outside of the system interface. There are three tiers inside: data tier (landsat/ETM/OLI, Terra/Aqua/MODIS, DMSP/OLS, etc.), computation tier (python modules), processing tier (basic operations, data pre-processing, image enhancement, image classification, image interpretation, data analysis, etc.). There are eight modules for students to make their personalized learning contents: four basic modules (pre-processing, image classification, data analysis, and an example of Donghu lake area change in Wuhan) and four optional advanced modules (city urbanization, land surface temperature and urban heat island effect, human activities observation using nighttime light data, and road extraction from satellite images) (Xi et al, 2012.).

\subsection{Implementations}

There exists a huge technical barrier for teachers to apply the technologies in the ordinary classrooms (Cheung et al, 2011). Remote labs are a technological response to bring education to an increasing number of communities, with the same level of reality perception as in a traditional (hands-on) lab. Remote labs provide real world measurements whenever a user interacts remotely and instantaneously with the lab system. In the last decade, remote laboratories arose with two major combined objectives: the first was to provide a higher number of students with the opportunity to learn by experimenting through the use of remote resources; the second was to allow institutions to control their budgets since remote labs can reduce the cost of classrooms and labs. A fringe benefit they bring is to allow institutions to easily share remote labs. For countries in deep economic difficulties, this approach is definitely attractive (Viegas et al, 2018). In higher education e-learning material is mainly spread for supporting students in preparation or repetition of topics. But there is a trend towards blended learning, combining traditional face-to-face classroom education with online course content. In many cases material is developed for basic courses only with high student numbers. Maintenance and sustainability often cause problems, but learning management systems offering discussion forums, wikis and blogs, and software toolkits for rapid content developments and students' assessments are valuable instruments supporting administrators as well as instructors (König, 2012).

Computers with internet access are usually the basic devices that are necessary for online learning. The basic set up requires screens through which lectures could be delivered, or content is made visible to read, also required are audio devices for delivery of study content as well as communication, discussion, and other interactions. Education is easily accessible to everyone (Deshwal et al, 2017). Different students may use this environment in different tiers, because their learning devices and data transfer rate are different. Data tier provides data transmission from server, and students accomplish the computation and processing process in their personal computers. This is the past learning approach, and it is still useful because students can download data before learning courses and apply the data with different methods and different parameters as many times as they want. Computation tier user can greatly decrease the file size of data transmission, especially after image mosaic and image cutting. Processing tiers users accomplish all the learning modules on the server. Downloading raw data and installing processing software are not needed any more, and the students can decrease the cost of learning and focus on the remote sensing applications. If a student gets an idea needed to be verified by remote sensing data, he can just open his personal computer (maybe cell phone after few years), connect to the server, perform several operations and retrieve the results. This web-based learning environment can stimulate the students' motivation after their ideas conveniently verified. Being positively motivated to take an online course of study, students, nevertheless, face a number of challenges while learning at a distance. These involve low self-organization, lack of control on the instructor's side, lack of effective interaction and sense of isolation, which obviously decrease their satisfaction with online learning experience (Markova et al, 2017).

The Python programming language and flask framework are chosen to implement the web-based remote sensing learning environment. Python code is easy to read, easy to learn still a very powerful language. Python is an open-source language, and it has libraries for just about everything, including remote sensing image data processing. The web-based learning environment is implemented in a local network server, including the remote sensing data processing algorithms and many satellite image data. Students can easily learn the remote sensing experimental courses by connecting to the local network server.

\section{THE LEARNING MODULE "DONGHU LAKE AREA CHANGE IN WUHAN"}

Some features of the learning environment are presented by the example of the learning module "Donghu lake area change in Wuhan". This module is one of the basic modules. After accomplishing three front basic modules, a comprehensive module is needed to show the application of remote sensing data. Lake area change is an important topic, because it is driven by climate change and human activities and linked to city urbanization, heat island, and etc. Comparing to the four tasks in the advanced modules, the classification between water and land is more obvious and easy to apply (Harris et al, 1989).

Here is some background of the Lake. Lake Donghu is located in Wuhan, Hubei Province $\left(30^{\circ} 33^{\prime} 33.0^{\prime \prime} \mathrm{N}, 14^{\circ} 24^{\prime} 38.5^{\prime \prime} \mathrm{E}\right)$ with a north subtropical monsoon humid climate having both abundant rainfall and sunshine. In general, the lake water level begins to rise after March each year and remains relatively high from May to August before dropping after September and staying relatively low through March. The average annual water retention time for Lake Donghu is $0.44 \mathrm{a}$, and the water depth is approximately $2.2 \mathrm{~m}$ with a coverage area of $36 \mathrm{~km}^{2}$. The monthly average temperature distribution shows the obvious characteristics of seasonal changes. The average temperature is $28.8^{\circ} \mathrm{C}$ in July and $4.5{ }^{\circ} \mathrm{C}$ in January. The maximum water temperature is usually found during July and August, and slightly exceeds 30 , with the minimum in February of approximately 5 . The characteristics of the inter-annual variability of the temperature indicate obvious continental climatic characteristics. That is, the average temperature 
gradually increases from January to July and decreases from August to December month-by-month. Lake Donghu is one of the largest urban lakes in China. The entire lake area is surrounded by urban architecture and easily influenced by human activities (permanent population of 110.8 million in Wuhan for 2018). Thus, the change of water boundary have occurred more frequently in recent decades (Chen et al, 2020).
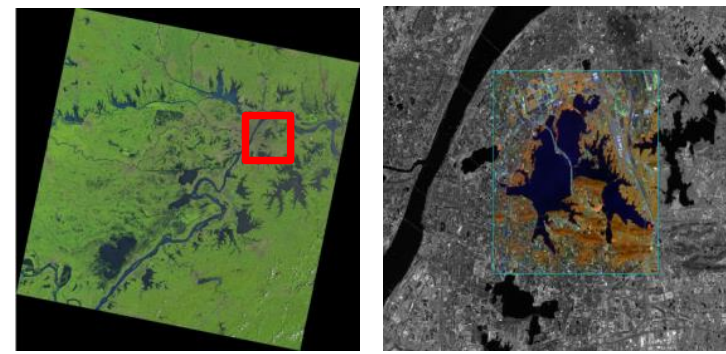

Figure 2. Location of lake Donghu in Landsat image

Monitoring and grasping the urban lake area changes objectively and accurately is the beginning of urban lake ecological service research. Accordingly, remote sensing technology has been widely used for water change monitoring since the 1970s. From traditional network monitoring of hydrological observation to the comprehensive monitoring stage with combination of satellite image, remote sensing technology has been applied into water body identification, flood monitoring, and water resources management. Complex surroundings, such as buildings, mountains, vegetation and bare land, makes it hard to extract water completely. For instance, it's difficult to distinguish the colour differences between water bodies and the shadows of buildings or mountains (Yang et al, 2015).

The remote sensing data are manly from Landsat 7 ETM and Landsat 8 OLI. The data from 1999 to 2019 can show the lake area changes in the past 20 years. Within the module, students perform the processing steps of Landsat image analysis. There are many different parameters to be determined by the users: image cutting border, bands selection, regions of interest, classification methods and parameters, etc.

There are three popular water extraction methods in the module: the spectrum-photometric method (SPM), the normalized difference water index (NDWI), the modified normalized difference water index (MNDWI). SPM mainly uses the advantage of multi-band to extract water information synthetically. On the other hand, water index methods are to use the strong water reflection bands and the weak ones to extract water by calculating their ratio. NDWI is proposed based on Normalized Difference Vegetation Index (NDVI). NDWI does improve the phenomenon that single-band threshold method brings a lot of noise. But in many cases, NDWI still hasn't been very successful yet, especially in the scope of city. Therefore, after analyzing urban water body and the background, MNDWI is proposed to extract urban water better. Nevertheless, each method has some limitations. The water spectrum photometric model can easily confuse these land types, which says the method doesn't have universality. NDVI just considered the factor of vegetation and ignored another important type of land surface: building. Building's spectral features in green band and near-infrared band almost like the water's. It's easy to mix buildings and water, and produce noises. Obviously, it will not achieve satisfactory result to use NDWI to extract water with the background of many buildings, such as city water. On the basis of NDWI, and MNDWI are improved in some respects. But each method can still not extract the water information completely. It's better to combine the advantages of these four methods and cast aside their defects.

Figure 3 shows some results of the lake boundary detection with different parameters. A default processing path with default methods and parameters is prepared for the beginners. Anyone can retrieve a result within the module by pressing enter key.
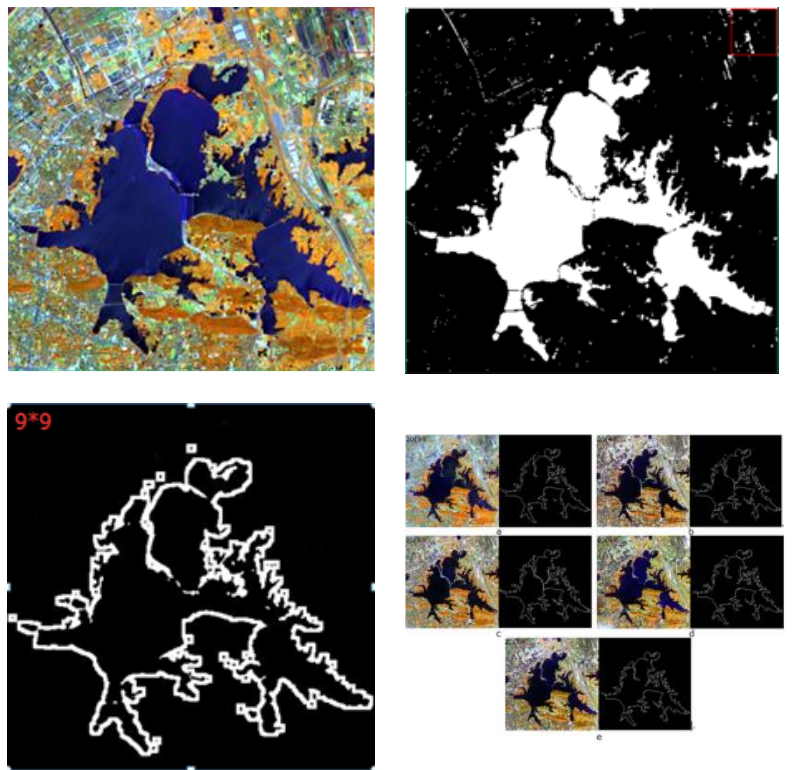

Figure 3. Results of the lake boundary detection

\section{CONCLUSIONS AND FUTURE WORKS}

In this article, the features of a web-based learning environment for remote sensing experimental class are presented. It may be very useful as the online education promoted because of Corona Virus Disease 2019. The results are encouraging and some recommendations will be extracted for the future.

Future work will be considered for the improvement in flexibility and functionality of the learning environment. It includes: (1) every year after the remote sensing experimental class, students can check their ideas with remote sensing data, and upload them to the new modules. It extends the topics to more fields. (2) A graphical user interface can decrease the skill requirement, and attracts more users besides college students. (3) Cell phone as the operation device can make the connection more convenient.

\section{ACKNOWLEDGEMENTS}

This work was supported by the research grants from the programme of teaching reform of Wuhan University of Science and Technology (2016X064, 2014Z010, YJG201432), and the research grants from the teaching programme of Hubei province (2018251).

Some data sets are provided by International Scientific \& Technical Data Mirror Site, Computer Network Information Center, Chinese Academy of Sciences 


\section{REFERENCES}

Al-Fraihat, D., Joy, M., Masa'deh, R., Sinclair, J., 2020. Evaluating E-learning systems success: An empirical study. Computers in Human Behavior, 102, 67-86.

Anjana, V., Gerhard, K., 2016. E-learning in photogrammetry, remote sensing and spatial information science. Int. Arch. Photogramm. Remote Sens. Spatial Inf. Sci., XLI-B6, 45-52.

Chen, Q., Huang, M.T., Tang, X.D., 2020. Eutrophication assessment of seasonal urban lakes in China Yangtze river basin using Landsat 8-derived Forel-Ule index: A six-year (20132018) observation. Science of The Total Environment, in press.

Cheung, Y., Pang, M., Lin, H., Lee, C.K.J., 2011. Enable spatial thinking using GIS and satellite remote sensing-a teaching-friendly approach. Procedia Social and Behavioral Sciences, 21, 130-138.

Deshwal, P., Trivedi, A., Himanshi, H.L.N., 2017. Online learning experience scale validation and its impact on learners' satisfaction. Procedia Computer Science, 112, 2447-2454.

Erik Stubkjær, 1997. The World Wide Web and university education in remote sensing. ISPRS Journal of Photogrammetry \& Remote Sensing, 52, 281-293.

Gülch, E., Al-Ghorani, N., Quedenfeldt, B., Braun, J., 2012. Evaluation and development of e-learning tools and methods in digital photogrammetry and remote sensing for non experts from academia and industry. Int. Arch. Photogramm. Remote Sens. Spatial Inf. Sci., XXXIX-B6, 45-52.

Haack, B., Ryerson, R., 2016. Improving remote sensing research and education in developing countries: Approaches and recommendations. International Journal of Applied Earth Observation and Geoinformation, 45, 77-83

Harris. A.R., Mason, I.M., 1989. Lake area measurement using AVHRR a case study. Int. J. Remote Sens., 10, 4-5.

Heradio, R., Torre, L., Galan, D., Cabrerizo, F.J., HerreraViedma, E., Dormido, S., 2016. Virtual and remote labs in education: A bibliometric analysis. Computers \& Education, 98, $14-38$

König, G., Shih, P.T.Y., Katterfeld, C., 2012. E-learning - best practice in photogrammetry, remote sensing and GIS - Status and challenges. Int. Arch. Photogramm. Remote Sens. Spatial Inf. Sci., XXXIX-B6, 91-96.

Li, J.Z., Yan, H., Yang, M.M., 2014. The application of agricultural remote sensing in remote sensing teaching practice. Advanced Materials Research, 926-930, 4626-4629.

Markova, T., Glazkova, I., Zaborova, E., 2017. Quality issues of online distance learning. Procedia - Social and Behavioral Sciences, 237, 685-691.

Raju, P.L.N., Gupta, P.K., 2012. Satellite based education and training in remote sensing and geo-information: An e-learning approach to meet the growing demands in India. Int. Arch. Photogramm. Remote Sens. Spatial Inf. Sci., XXXIX-B6, 2529.
Shi, D.Q., Wang. T., Xing, H., Xu, H., 2020. A learning path recommendation model based on a multidimensional knowledge graph framework for e-learning. Knowledge-Based Systems, 195,15618

Viegas, C., Pavani, A., Lima, N., Marques, A., Pozzo, I., Dobboletta, E., Atencia, V., Barreto, D., Calliari, F., Fidalgo, A., Lima, D, Temporão, G., Alves, G., 2018. Impact of a remote lab on teaching practices and student learning. Computers \& Education, 126, 201-216.

Wolf, N., Fuchsgruber, V., Riembauer, G., Siegmund, A., 2016. An adaptive web-based learning environment for the application of remote sensing in schools. Int. Arch. Photogramm. Remote Sens. Spatial Inf. Sci., XLI-B6, 53-56.

Xi, W.J., Peng Y.M., Yang, Y.Y., Luo., R.Z., Lin., Y., 2012. Research of experiment teaching contents reconstruction of remote sensing technology course. Advanced Materials Research, 518-523, 5817-5821.

Yang, B.H., Ke, X.L., 2015. Analysis on urban lake change during rapid urbanization using a synergistic approach: A case study of Wuhan, China. Physics and Chemistry of the Earth, 89-90, 127-135

Yang, Z.L., Cao, J., Hu, K., Gui, Z.P., Wu, H.Y., You, L, 2016. Developing a cloud-based online geospatial information sharing and geoprocessing platform to facilitate collaborative education and research. Int. Arch. Photogramm. Remote Sens. Spatial Inf. Sci., XLI-B6, 3-7. 